108 Zhan, X-M . and Yang, X-J . (2001) Temporal and spatial effects of Sonic hedgehog signalling in chick eyemorphogenesis. Dev. Biol. 233, 271-290

109 J ensen, A.M. and Wallace, V. (1997) Expression of Sonichedgehog and its putativeroleas a precursor cell mitogen in the developing mouse retina. Development 124, 363-371

110 Levine, E.M. et al. (1997) Sonichedgehog promotes rod photoreceptor differentiation in mammalian retinal cells in vitro. J . Neurosci. 17, 6277-6288

111 Neurmann, C.J . and Nuesslein-Volhard, C. (2000) Patterning of the zebrafish retina by a wave of Sonic hedgehog activity. Science289, 2137-2139

112 Stenkamp, D.L. et al. (2000) Function for hedgehog genes in zebrafish retinal development. Dev. Biol. 220, 238-252
113 Dominguez, M. and Hafen, E. (1997) hedgehog directly controls initiation and propagation of retinal differentiation in the Drosophila eye. Genes Dev. 11, 3254-3264

114 Zhan, X-M. and Yang, X-J . (2001) Regulation or retinal ganglion cell production by Sonic hedgehog. Devel opment 128, 943-957

115 Trousse, F. etal. (2001) Control of retinal ganglion cell axon growth: a new role for Sonic hedgehog. Devel opment 128, 3927-3936

116 Torres, M. et al. (1996) Pax2 contributes to inner ear patterning and optic nervetrajectory. Devel opment 122, 3409-3418

117 Macdonald, R. et al . (1997) The Pax protein Noi is required for commissural axon pathway formation in the rostral forebrain. Development $124,2397-2408$
118 Testaz, S. et al. (2001) Sonic hedgehog restricts integrin-mediated migration of neural crest cells through an alternative patched-independent signalling pathway. Proc. Natl. Acad. Sci. U. S. A. 98, 12521- 12526

119 Muhr, J .etal. (2001) Groucho-mediated transcriptional repression establishes progenitor cell pattern and neuronal fatein the ventral neural tube. Cell 104, 861-873

120 Song, H.J . and Poo, M.M. (1999) Signal transduction underlying growth coneguidance by diffusiblefactors. Curr. Opin. Neurobiol. 9, 355-363

121 Goulding, M. and Lamar, E. (2000) Neuronal patterning: Making stripes in the spinal cord. Curr. Biol. 10, R565-R568

\title{
Neural encoding of behaviourally relevant visual-motion information in
} thefly

\author{
Martin Egelhaaf, Roland Kem, Holger G. Krapp,J utta Kretzberg, Rafael Kurtz and \\ Anne-Kathrin Warzecha
}

\begin{abstract}
Information processing in visual systems is constrained by the spatial and temporal characteristics of the sensory input and by the biophysical properties of the neuronal circuits. Hence, to understand how visual systems encode behaviourally relevant information, we need to know about both the computational capabilities of the nervous system and the natural conditions under which animals nomally operate. By combining behavioural, neurophysiological and computational approaches, it is now possible in the fly to assess adaptations that process visual-motion information under the constraints of its natural input. It is concluded that neuronal operating ranges and coding strategies appear to be closely matched to the inputs the animal encounters under behaviourally relevant conditions.
\end{abstract}

Martin Egelhaaf* Roland Kem J utta Kretzberg Rafael Kurtz Anne-Kathrin Warzecha Lehrstuhl für Neurobiologie, Fakultät für Biologie, Universität Bielefeld, Postfach 1001 31, D-33501 Bielefeld, Germany. *e-mail:martin.egelhaaf@ biologie.uni-bielefeld.de

Holger G. Krapp Dept of Zoology, University of Cambridge, Downing Street, Cambridge, UK CB2 3E]
The goal of neuroethology is to explain behaviour in terms of theactivity of nervecells and their interactions. This can only beachieved if the experimental animal can beanalysed at different levels ranging from behaviour toindividual neurons. Cellular mechanisms underlying processing of neuronal information are frequently analysed using in vitropreparations where artificial stimulation replaces thenatural sensory input. Although such studies providefascinating insights into thecomplex computational abilities of neurons [1], the results may not beextrapolated easily toin vivo conditions, wheretherange of responseamplitudes of neurons and their temporal activity patterns may differ considerably from artificially induced activity. In systems such as the retina of the horseshoecrab
Limulus [2], and various brain areas of pigeons [3], cats [4] and monkeys [5,6], it is now feasibleto analyse theneuronal representation of visual input as it is experienced during behaviour (reviewed in Refs $[7,8]$ ). Until now, however, in most systems theunderlying neuronal mechanisms havebeen difficult to unravel.

In the fly it is possible to employ both quantitative behavioural approaches as well as in vivo el ectrophysiological and imaging methods to analyse how behaviourally relevant visual input is processed [9-20]. Although the latter techniques aremainly employed in the blowfly, which is relatively big, they arecomplemented by studies of the smaller fruitfly, Drosophila, wherea broad range of genetic approaches can beapplied to dissect the visual system in an increasingly specific way [21,22].

Wereview recent progress on the encoding of optic-flow information in theblowfly. Optic flow is an important source of information about self-motion and thethree-dimensional layout of the environment, not only for flies but for most moving animals including humans (Box 1, [4,23-25]). Flies exploit optic flow to guidetheir locomotion [13] and to control compensatory head movements [26], and understanding the computational principles underlying optic-flow processing in flies could provide insights intovisual-motion analysis in general. 
Box 1. Processing of optic flow in the fly visual system

During locomotion the entire retinal image is continually displaced. This optic flow depends on the particular type of self-motion and on the three-dimensional layout of the environment (Fig. Ia) [a,b]. Optic flow is characterized by global rather than local features. This imposes constraints on the neuronal mechanisms that evaluate optic flow as measurements of local motion from large areas of the visual field need to be combined. Accordingly, in animal taxa from insects to primates, neurons sensitive to optic flow were found to have large receptive fields (reviewed in Ref. [c]).

In the fly, the combination of local-motion measurements takes place in a strictly retinotopic way on the extended dendritic trees of a set of so-called tangential cells (TCs) (Fig. Ib). About 50 TCs of different individual morphology and functional properties have been identified in each half of the brain and found to respond to different aspects of optic flow [d-g]. Spatial pooling of local motion information is highly nonlinear. This computational feature is the consequence of both the input organization of TCs and their biophysical properties [f,h-I].

Spatial pooling of local-motion information from one eye is not usually sufficient to analyse the various types of optic flow with a high specificity. For instance, during forward translation the optic flow across both eyes is directed backwards (Fig. Ia). In contrast, during a pure rotation about the vertical axis, optic flow is directed backwards across one eye, but forwards across the other eye. Hence, translational and rotational self-motion can be distinguished by taking into account motion information from both eyes, a computational strategy used by many animals with lateral eyes, such as pigeons, rabbits and many insect species [m-p]. In the fly, specificity for certain types of optic flow is achieved by synaptic interactions between TCs in the ipsi- and/or contralateral half of the visual system (Fig. Ib) [d,e,q-t]. As a consequence, some TCs respond best to the optic flow induced when an animal turns about one of its body axes. Other TCs are tuned to relative motion between an object and its background $[e, f]$.

\section{References}

a Gibson, J .J . (1979) TheE col ogical Approach to Visual Perception, Houghton Mifflin, Boston

b Koenderink, J J . (1986) Opticflow. Vis. Res. 26, 161-180

c Lappe, M., ed. (2000) Neuronal Processing of Optic Flow, Academic Press

d Hausen, K. (1981) Monocular and binocular computation of motion in the lobula plate of the fly. Verh. Dtsch. Zool. Ges. 74, 49-70

e Hausen, K. and Egelhaaf, M. (1989) Neural mechanisms of visual course control in insects. In Facets of Vision (Stavenga, D.G. and Hardie, R.C., eds), pp. 391-424, Springer

f Egelhaaf, M. and Borst, A. (1993)A look into the cockpit of thefly: Visual orientation, algorithms, and identified neurons. J . Neurosci. 13, 4563-4574

g Krapp, H. (2000) Neuronal matched filters for optic flow processing in flying insects. In Neuronal Processing of OpticFlow (Lappe, M., ed.), pp. 93-120, AcademicPress

h Borst, A. et al. (1995) Mechanisms of dendriticintegration underlying gain control in fly motion-sensitiveinterneurons. J . Comput. Neurosci. 2, 5-18

i Haag, J . and Borst, A. (1998) Activemembrane properties and signal encoding in graded potential neurons. J . Neurosci. 18, 7972-7986

j Haag, J . etal. (1997) Theintrinsic electrophysiological characteristics of fly lobula plate tangential cells: II . Activemembrane properties. J . Comput. Neurosci. 4, 349-369

k Single, S. et al. (1997) Dendritic computation of direction sel ectivity and gain control in visual interneurons. J . Neurosci. 17, 6023-6030

I Haag, J . et al. (1999) Theintrinsic electrophysiological characteristics of fly lobula plate tangential cells: III. Visual response properties. J . Comput. Neurosci. 7, 213-234

m Frost, B.J . and Wylie, D.R.W. (2000) A common frame of reference for the analysis of optic flow and vestibular information. In Neuronal Processing of OpticFlow (Lappe, M., ed.), pp.121-140, AcademicPress

n Simpson, J .I . (1984) Theaccessory optic system. Annu. Rev. Neurosci. 7, 13-41

Tounderstand thesignificance of the mechanisms involved in optic-flow processing, weshould consider the behavioural context in which opticflow is generated. In thefollowing, wesummarize: (1) the (a)

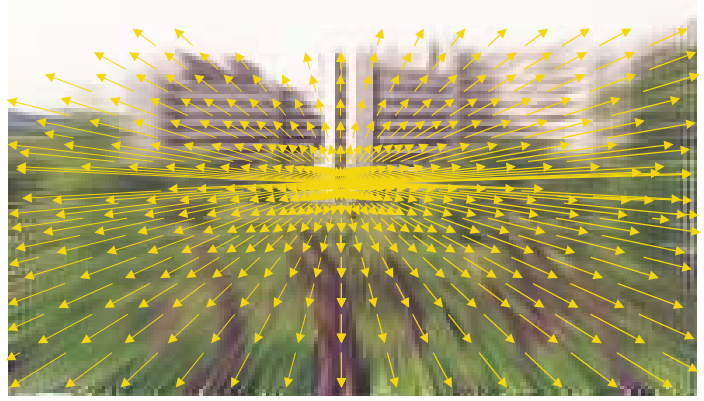

(b)

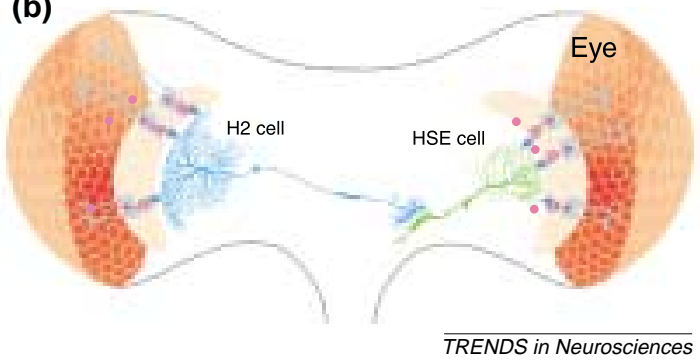

Fig. I. (a) Optic-flow field elicited when approaching an object on a straight course (forward translation). The arrows indicate schematically the velocity vectors of image points on the retina. During forward translation, velocity vectors point backwards from a focus of expansion in the middle of the visual field. (b) Schematic of the visual motion pathway of the fly (caudal view). The compound eyes are indicated in orange. The visual system is organized in a retinotopic way by columnar elements. Synaptic interactions within as well as between, columns lead to motion-sensitive responses (for details see Refs $[11,28])$. The outputs of such small-field motionsensitive elements are pooled spatially by the large dendrites of tangential cells (TCS). Two types of TC (the HSE cell and H2 cell) are shown. The HSE cell receives additional input from the $\mathrm{H} 2$ cell and from the $\mathrm{H} 1$ cell (not shown), and thus integrates visual-motion information from both eyes. Reconstructions of HSE- and $\mathrm{H} 2$ cells courtesy of K. Hausen.

o I bbotson, M.R. (1991) Wide-field motion-sensitiveneurons tuned to horizontal movement in thehoneybee, Apis mellifera. J . Comp. Physiol. A 168, 91-102

p Kern, R. (1998) Visual position stabilization in the hummingbird hawk moth, Macrogl ossum stellatarum L.: II . Electrophysiological analysis of neurons sensitiveto widefield image motion. J . Comp. Physiol. 182, 239-249

q Krapp, H.G. etal. (2001) Binocular contribution to opticflow processing in thefly visual system. J . Neurophysiol. 85, 724-734

r Strausfeld, N.J .et al. (1995) Oculomotor control in Calliphorid flies: GABAergic organization in heterolateral inhibitory pathways. J . Comp. Neurol. 361, 298-320

s Horstmann, W. et al. (2000) Synaptic interactions increase opticflow specificity. Eur.J . Neurosci. 12, 2157-2165

t Haag, J . and Borst, A. (2001) Recurrent network interactions underlying flow-field selectivity of visual interneurons. J. Neurosci. 21, 5685-5692

sophisticated organization of retinotopic input in neurons processing opticflow; (2) the combination of optic-flow information from both eyes; (3) theaccuracy with which motion information can beevaluated; and 


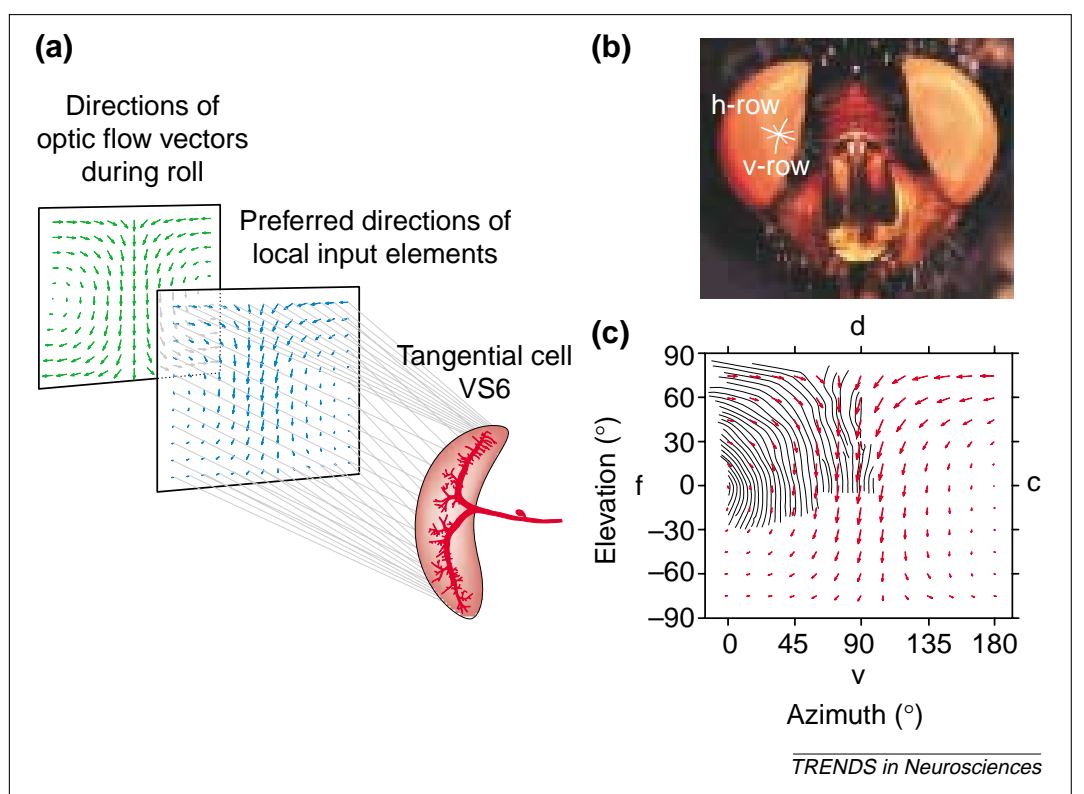

Fig. 1. Retinotopic input organization of tangential cells (TCs). (a) Self-motion generates panoramic optic flow over the eyes. The green arrows represent the local motion vectors on the eye when the animal rolls around its longitudinal body axis. The local response properties of a TC, the VS6 cell, are adapted to detect this particular self-rotation. It is assumed that with its large dendrite the cell integrates signals from local input elements whose preferred directions (blue arrows) correspond to the direction of local motion vectors in roll-induced optic flow. (b) Head of a female blowfly (Calliphora vicina). White lines over the right eye indicate the course of ommatidial rows in the hexagonal eye lattice. (Photograph courtesy of R. Hengstenberg.) (c) Organization of the receptive field of a VS6 cell. Orientation and length of arrows at different angular positions indicate the neuron's local preferred direction and motion sensitivity in the right visual hemisphere. $0^{\circ}$ azimuth and $0^{\circ}$ elevation corresponds to the point directly in front of the animal. f, c, d, and v refer to the frontal, caudal, dorsal and ventral aspects of the visual field. Black lines in the upper-left quadrant indicate the course of ommatidial rows, which are orientated vertically in the equatorial region of the eye ( $\mathrm{v}$-row). The direction of visual motion is thought to be analysed mainly by interactions between ommatidia along the rows in the hexagonal eye lattice (c.f. orientation of rows and arrows). In the dorso-frontal eye region the course of the $v$-rows strongly shifts towards a horizontal orientation. This change in orientation is reflected by the change in local preferred directions of VS6 cells in corresponding regions of its receptive field. Experimental data from Refs [29,32].

(4) theneuronal performanceunder stimulus conditions that occur during activelocomotion.

\section{Exploiting global features of optic flow by spatial pooling of retinotopic inputs}

The motion vectors describing the local image displacements on the retina are not constant across thevisual field, but changein a characteristic way depending on self-motion (see Box 1). Flies can exploit theglobal features of optic flow to gain neuronal representations of self-motion [12,27]. This is accomplished by the organization of the spatial input of the tangential cells (TCs, see Box 1 ). The large dendritictrees of TCs pool the outputs of many retinotopically organized small-fiel d elements, which are thought to estimate the direction of local retinal-imageshifts $[11,28]$. The preferred directions of the small-field el ements that synapse onto a given TC appear to coincidewith the directions of the velocity vectors characterizing the optic flow induced during particular types of self-motion (Fig. 1a) $[27,29,30]$. The sophisticated global patterns of preferred directions do not depend on visual experience and thus represent phylogenetic rather than developmental adaptations to optic-flow analysis [31].

Thecomputation of self-motion based on opticflow is facilitated by the geometry of the compound eye lattice(Fig. 1b). Theorientations of ommatidial rows along which directional motion is thought to be computed coincide with the local preferred directions of particular TCs, and thus with the direction of local velocity vectors that occur during locomotion, for instance, during forward translation or rotation around theanimal's longitudinal body axis (Fig. 1c) $[12,32,33]$. Matching the geometrical properties of the compound eyetothegl obal structure of frequently encountered opticflow all ows the sophisticated input organization of someTCs to be established by interactions al ong the anatomical rows of the compound eyein what is a rather simplewiring scheme. Hencethegeometry of thefly compound eye appears to bea phylogenetic adaptation to parsimonious processing of opticflow. Similarly, the design of crab eyes is adapted tolifein different habitats [34] and the sensitivity distribution of photor eceptors of bees and ants depends on the celestial pattern of polarized light [35]. Moreover, locomotion in primates is likely to bea phyologenetic determinant of the topography of the visual system [36]. These examples indicatethat visual systems makeuse of predictablesensory input to find low-level computational solutions to seemingly high-level tasks.

\section{Combining information on optic flow from both eyes} Integration of motion signals from one eyeis often not sufficient toyield a high specificity of TCs with respect to particular types of self-motion, such as rotation or translation. By combining motion information from both eyes (Box 1) specificity may be greatly enhanced. This is accompl ished by TCs that convey motion information gathered within thevisual field of one eye to the contralateral side of the brain where they interact with other TCs [12,13,30,37-39]. Unless the intervening synapse is car efully adjusted to the presynaptic activity levels that occur during sensory stimulation, synaptic transmission may distort theinformation being transmitted. This hazard is particularly daunting becausesignal transfer across synapses is inherently noisy and, in many systems, is nonlinear (reviewed in Refs [40,41]).

Combined electrophysiological and optical-imaging experiments (Figs $2 \mathrm{a}, \mathrm{b}$ ) reveal that, despitethese potential nonlinearities, theentirerange of depolarization levels that can beelicited by motion in the 'preferred direction'in the presynapticterminal of aTC is transformed approximately linearly intothe spikerate of the postsynaptic TC. Therelationships between presynaptic potential and presynaptic $\mathrm{Ca}^{2+}$ concentration (thelatter representing a second messenger invol ved in transmitter rel ease) and between presynaptic $\mathrm{Ca}^{2+}$ concentration and postsynaptic spikeratearealso linear (Fig. 2c). Motion in theantipreferred direction hyper pol arizes the 


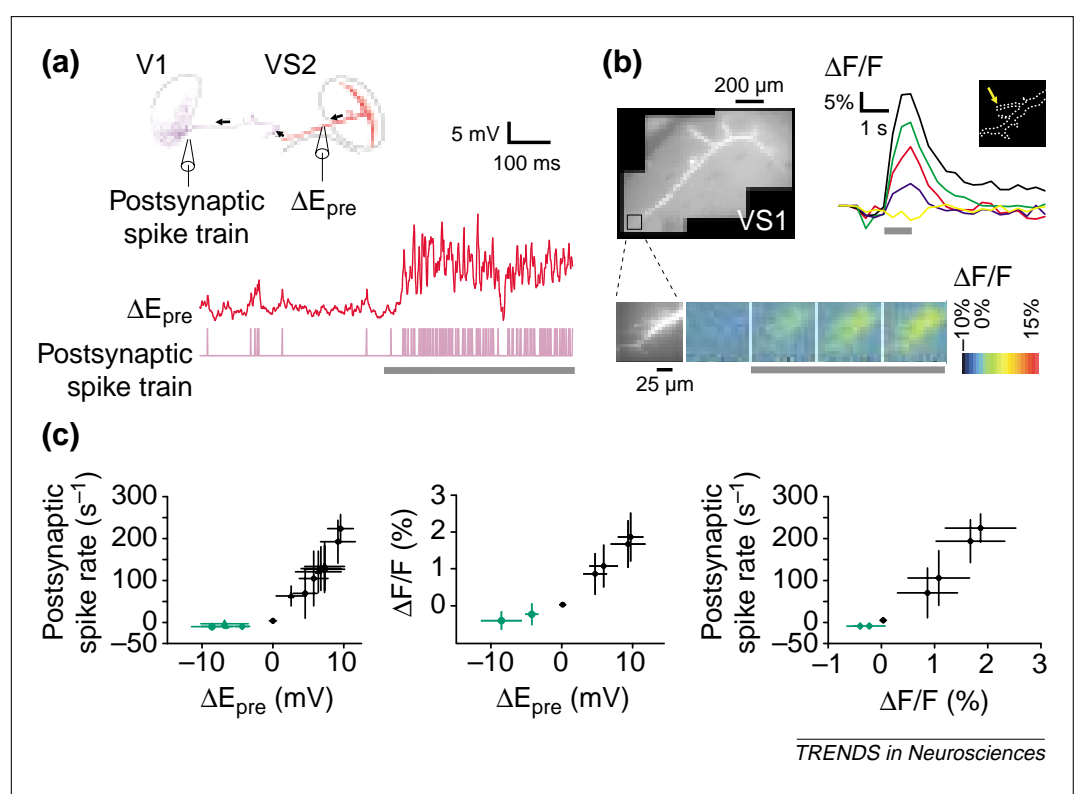

Fig. 2. Transmission of optic flow information between a pair of tangential cells (TCS). (a) The V1TC receives input from VS (vertical system) TCs and transmits this motion information to the contralateral visual system, where it forms an extended output arborization. Presynaptic membrane potential changes $\left(\Delta \mathrm{E}_{\mathrm{pre}}\right)$ and postsynaptic spike trains (occurrence of a spike indicated by a vertical line) are recorded simultaneously in vivo. Visual motion in the preferred direction (grey horizontal bar) leads to depolarization of the presynaptic cell and to an increase in postsynaptic spike rate. (b) Presynaptic $\mathrm{Ca}^{2+}$ accumulation in a VS cell filled with a $\mathrm{Ca}^{2+}$-sensitive fluorescent dye (raw fluorescence images of the entire cell and of the presynaptic region, left diagrams) during presentation of preferred direction motion (grey horizontal bar). Warm colours in the colour-coded images correspond to increases in $\mathrm{Ca}^{2+}$ concentration (measured as relative change in fluorescence: $\Delta F / F$ ). The time course of the change in presynaptic $\mathrm{Ca}^{2+}$ concentration is plotted for variable stimulus strengths (coloured lines, upper right diagram). The inset in the upper right diagram shows the outline of the terminal region (dotted line) as seen on the raw fluorescence image and the region of the presynaptic terminal over which the fluorescence change was spatially integrated (white area indicated by yellow arrow). (c) Linearity of the transfer of preferred direction motion. Left: Postsynaptic spike rate (relative to resting activity) is plotted versus the presynaptic membrane potential change $\left(\Delta \mathrm{E}_{\mathrm{pre}}\right)$ for visual stimuli of variable strengths, moving either in the preferred direction (blacksymbols) or in the null direction (green symbols). The gain of signal transfer is approximately constant for the entire range of visually induced excitations, resulting in a linear relationship between presynaptic potential and postsynaptic spike rate upon motion in the preferred direction. A rectification is prominent for motion in the null direction. Linear dependencies for preferred direction motion are also present in the relationship between changes in presynaptic $\mathrm{Ca}^{2+}$ and in presynaptic membrane potential (middle) and in that between postsynaptic spike rate and changes in presynaptic $\mathrm{Ca}^{2+}$ (right). Electrophysiological and optical recording data reproduced from Ref. [42], cell reconstructions shown in (a) reproduced from Refs [13,29].

presynapticneuron, whereas both the presynaptic $\mathrm{Ca}^{2+}$ concentration and the postsynaptic spikerate decrease only slightly bel ow their resting levels. Thus, apart from this rectification, motion information is transmitted largely undistorted to the contralateral visual system [42] with a functional consequence that thesynaptic transfer does not affect the dependence of the motion signals on thestimulus parameters, such as the velocity of motion.

\section{Accuracy of encoding of optic flow information}

There are constraints to coding of stimuli imposed by noise and spikegeneration in any system. Noise leads to variableneuronal responses to repeated presentation of thesamestimulus (Fig. 3a). Although the variancein spike count across trials of fly TCs is small compared to motion-sensitiveneurons in the primatecortex $[43,45]$, variability in theneuronal responseconstrains the precision with which stimulus events can be encoded by the timing of spikes and, thus, theaccuracy with which timevarying optic-flow characteristics of behavioural situations can beconveyed.

Analysis of spiketrains shows that the precision of spiketiming depends on stimulus dynamics. Spike generation per sedoes not limit the accuracy of representing motion information, becausespikes time-lock torapid fluctuations in membrane potential with a millisecond precision [46-48]. As a consequence, spikes aretime-locked precisely to a stimulus only if thestimulus-induced changes in membrane potential aresufficiently fast and large, relativeto membrane-potential noise. In contrast, slow stimulus-induced fluctuations in membrane potential mainly affect the spikerateand normally do not cause precisetime-locking of spikes; the exact timing of spikes is then determined by thehighfrequency components of themembranepotential noise (Fig. 3b) [49]. Because computations that underliedirection sel ectivity inevitably requiretime constants of sometens of milliseconds [50], they attenuatetheneural responses to high-frequency velocity fluctuations (Fig. 3c) [51,52]. Hence, TC depolarizations aresufficiently pronounced to elicit spikes with a millisecond precision only when the vel ocity changes are very rapid and large $[17,18,53]$. Otherwise, theexact timing of spikes is determined mostly by membrane-potential noiseand visual motion is represented by thespike rate.

Key evidence for these condusions is the finding that spikes in pairs of TCs with largely overlapping retinotopic input tend to besynchronized with a millisecond precision. This implies that both TCs sharehigh-frequency signals originating from their common input. As, on average, theseTCs are timelocked to velocity fluctuations with much less accuracy, it is suggested that thesynchronization is attributable to high-frequency noise in their common input and not to the stimulus (Fig. 3d) [49,52]. Although to what extent rapid- and slow velocity changes, and thus the exact timing of spikes, are functionally significant is still debated [17,18], it is generally agreed that this issuecan only beresolved by taking into account the dynamics of retinal-image displacements in different behavioural contexts.

\section{Evaluation of behaviourally generated optic flow}

The dynamics of optic flow are largely determined by the dynamics of the animal's self-motion. The direction of self-motion may change rapidly, such as during saccadic turns during flight $[54,55]$ or an order of magnitudemore sl owly, such as during walking [19]. Because it is not possible currently to record from neurons in freely moving flies, indirect approaches have been used to determinethe responses of TCs to behaviourally generated optic flow. Recordings can be madefrom the brains of flies that are oscillated with dynamics that mimic the rotational self-motion component experienced in free flight [20]. In another approach, theoptic flow 


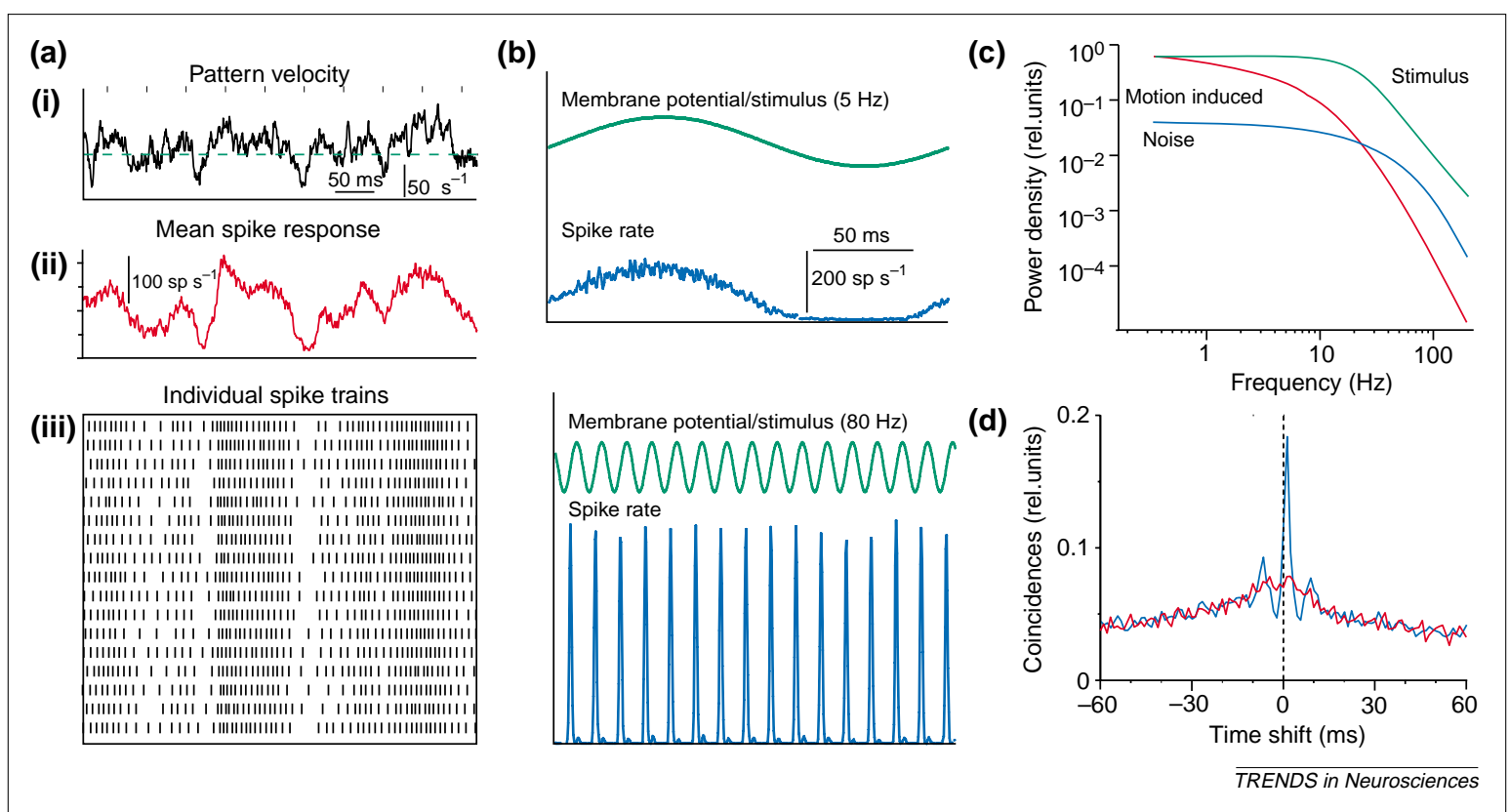

Fig. 3. Variability of neural responses and the accuracy with which optic-flow information is signalled. (a) Variability of spike activity of a tangential cell (TC), the H1 cell. Velocity profile of the motion stimulus. (i) Velocities above the dashed line denote motion in the preferred direction of the cell, velocities below the dashed line signal motion in the antipreferred direction. (ii) Spike rate of the $\mathrm{H} 1$ cell as a function of time. The response follows the overall time course of pattern velocity. (iii) Individual responses to repeated presentation of the same motion trace. Vertical lines denote spike occurrence. Although the overall pattern of neuronal activity is similar from trial to trial, there is variability in the temporal fine structure across trials (for details see Refs [44,52]). (b) Time-locking of spikes to sinusoidal stimulus-induced fluctuations in membrane potential $(5 \mathrm{~Hz}$ or $80 \mathrm{~Hz}$, green traces) in a model cell. The model is adjusted to fit the responses of a fly TC to motion stimuli. Noise is added to the stimulus-induced component of the membrane potential. The noise differs from presentation to presentation. Spike frequency histograms (blue traces) illustrate that fast stimulus-induced membrane potential fluctuations are needed to trigger spikes with a high temporal precision. Slow stimulus-induced fluctuations lead to spike activity with a rate approximately proportional to the membrane potential (for details see Ref. [49]). (c) Dynamic properties of membrane potential fluctuations in a fly TC (the HSE cell) elicited by band-limited white-noise velocity fluctuations; power spectra of the motion stimulus (green), the motioninduced response component (red) and the stochastic membrane potential fluctuations (blue). The motion-induced-response component was determined by averaging many individual response traces, thereby attenuating stochastic membrane-potential fluctuations. It contains most power below $20 \mathrm{~Hz}$, although the stimulus contained higher frequencies. In the low-frequency range, the motion-induced-response component is larger than the stochastic-response component. Athigher frequencies this relationship reverses (for details see Ref. [52]). (d) Cross-correlogram of the responses of two TCs ( $\mathrm{H} 1$ and $\mathrm{H} 2$ ) with common synaptic input to fluctuations in the velocity of band-limited white noise. Either synchronously recorded responses were used (blue trace) or responses that were not recorded synchronously but obtained from repetitive presentation with the same motion stimulus (red trace). Although TCs can generate spikes very precisely (blue trace), most spikes time-lock to dynamic-motion stimulation on a much coarser timescale (red trace) (for details see Ref. [52]).

experienced by moving flies was reconstructed and replayed to a fixed animal during nerve-cell recordings. This approach has been employed for various behavioural situations during tethered flight in a flight simulator $[56,57]$ and during unrestrained walking in a three-dimensional environment $[19,58]$. The results indicate that information obtained from optic flow about the layout of theenvironment [57] or theanimal's selfmotion [19] is much less ambiguous than concluded from earlier studies using conventional stimuli, such as moving gratings.

This condusion is exemplified in Fig. 4 by the performance of a TC (theHSE cell) whoseinput connections suggest a rolein signalling turns of the animal around its vertical axis [12,38,39]. Despite this input organization theHSE cell alsoresponds to translation and to changes in the texture of conventional stimuli $[12,13,19]$. Analyses using conventional stimuli indicatethat the cell's response is ambiguous. However, when challenged with optic flow generated during walking, most of these ambiguities disappear and the cell provides information about theanimal's turning direction largely independent of thetranslational optic-flow component and the layout of theenvironment (Fig. 4b) [19]. Model simulations indicatethat the computations underlying optic-flow processing are well matched to opticflow experienced in behavioural situations [59]. This is because: (1) natural stimuli are characterized by a wide range of spatial frequencies, in contrast to conventional grating patterns (seealso Ref. [60]); (2) thelocal-movement inputs of theTCs operate in a range where velocity is nolonger represented linearly; and (3) thenonlinear spatialintegration characteristics of TCs (see Box 1 ) make their responses largely independent of texture density.

Thecharacteristics of motion computation may differ in insect species that have different visually guided orientation behaviours and thus may be matched tothespatio-temporal properties of their different retinal inputs [61,62]. Moreover, the properties of fly TCs changeas a result of stimulus history [63-69]. Although the functional significance of theseadaptational processes is debated, they may 


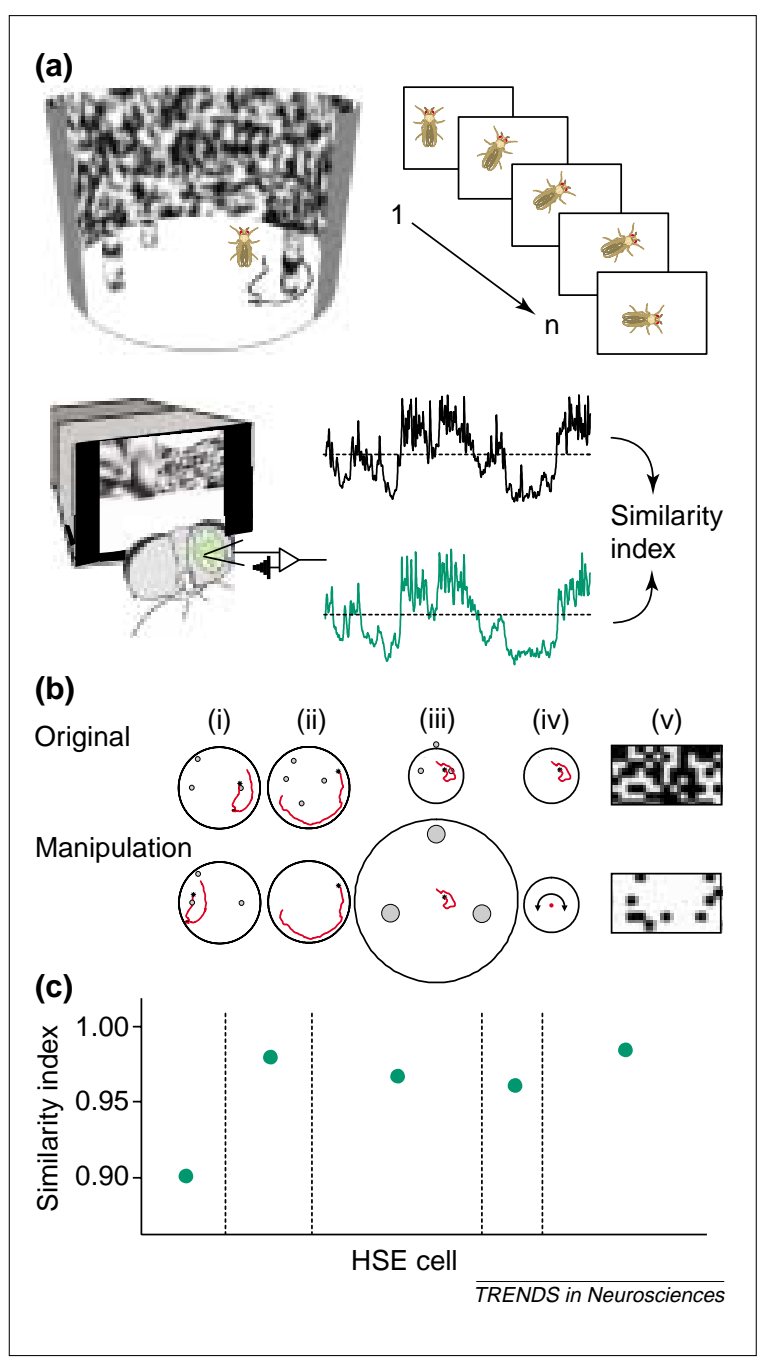

well play a rolein adjusting theoperating range of the mechanisms underlying optic-flow processing to different behavioural contexts.

\section{Acknowledgements}

We are grateful to G. Card,

S. Huston. S.B. Laughlin and T. Matheson

(University of Cambridge) and to I. Grewe

K. Karmeier and

J.P. Lindemann (Bielefeld University) for helpful comments on the manuscript. Workin our group is supported by the Deutsche

Forschungsgemeinschaft.
Fig. 4. Responses of a tangential cell (TC) to naturalistic optic flow. (a) The experimental approach. Flies walking freely in an arena are video-recorded and the position and orientation of the fly are determined in each digitized frame. The trajectory data are used to control the path of a simulated camera in a virtual 3D-environment that mimics the arena. The size of the field-of-view of the camera is adjusted to approximate the receptive field of the TC recorded in subsequent electrophysiological experiments. During an electrophysiological recording, the TC is visually stimulated by the sequence of reconstructed images. Recording traces are shown in response to simulated optic-flow sequences seen by the walking fly (black) and as seen on the same track in a manipulated virtual environment (green) (see below). (b) Original behavioural situation (upper diagrams) and manipulations (lower diagrams). The original walking trajectories are shown in red. The circles illustrate the arena as seen from above, with the position and the diameter of objects indicated by dots: (i) the original track was displaced to the opposite side of the textured arena; (ii) objects that were present during the original walk were removed in the playback; (iii) the textured arena was enlarged by a factor of 3.0, thereby reducing the translational optic-flow component; (iv) the translational component of the original walking track was eliminated in the playback so that the stimulus corresponded to a rotation around the arena centre; $(v)$ the original $50 \%$ black and white arena texture was replaced with a texture having $12 \%$ black elements in the playback. (c) Similarity of responses of the HSE cell to the original and manipulated optic flow stimuli as indicated in (b). A similarity index of one indicates that the time courses of responses to two different stimuli are as similar as the time courses of responses to the same stimulus. All tested manipulations of the environment (and thus of the visual input to a fly walking spontaneously in its environment) have little effect on the time course of the HSE-cell response (for details see Refs [19,59]).

most studies employing stimuli generated by the moving fly have been performed indoors. However, recently, responses of a fly TC were concluded to cover a larger dynamicrange and to be more reliablein bright sunlight than under dimmer laboratory conditions [20]. Although these conclusions are not accepted unanimously, and to what extent brightness affects neuronal performance is still debated [70], it is becoming increasingly clear that the visual system of the fly is exquisitely adapted to process the complex opticflow elicited in behavioural situations. Adaptations to natural operating conditions reveal themsel ves in thestructural properties of the compound eye, the specificfeatures of the mechanisms underlying motion computation, the spatial input organization of the TCs and thesignal transfer between them. Evolution has shaped thefly nervous system to solve efficiently and parsimoniously those computational tasks that are relevant to thesurvival of the species. In this way animals with even tiny brains are often capable of performing extraordinarily well in specific behavioural contexts.

\section{References}

1 Stuart, G. et al. (1999) Dendrites, Oxford University Press

2 Passaglia, C. etal. (1997) Deciphering a neural codefor vision. Proc. Natl. Acad. Sci. U.S. A. 94, 12649-12654

3 Frost, B.J . and Wylie, D.R.W. (2000) A common frame of referencefor theanalysis of optic flow and vestibular information. In Neuronal Processing of OpticFlow (Lappe, M., ed.), pp. 121-140, Academic Press

4 Sherk, H. and Fowler, G.A. (2000) Optic flow and the visual guidance of locomotion in the cat.
In Neuronal Processing of OpticFlow (Lappe, M., ed.), pp. 141-170, Academic Press

5 Pekel, M. et al. (1996) Neuronal responses in the motion pathway of the macaque monkey to natural optic flow stimuli. NeuroReport 7, 884-888

6 Gallant, J .L. etal. (1998) Neural activity in areas V1, V2 and V4 during free viewing of natural scenes compared to controlled viewing. NeuroReport 9, 85-90

7 Simoncelli, E.P. and Olshausen, B.A. (2001) Natural imagestatistics and neural representation. Annu. Rev. Neurosci. 24, 1193-1225
8 Reinagel, P. (2001) How do visual neurons respond in thereal world. Curr. Opin. Neurobiol. $11,437-442$

9 Laughlin, S.B. (1994) Matching coding, circuits, cells, and molecules to signals: General principles of retinal design in thefly's eye. Prog. Retinal Eye Res. 13, 165-196

10 J uusola, M. et al. (1996) I nformation processing by graded-potential transmission through tonically activesynapses. Trends Neurosci. 19, 292-297

11 Strausfeld, N.J . (1989) Beneath the compound eye: Neuroanatomical analysis and physiological 
correlates in the study of insect vision. In F acets of Vision (Stavenga, D.G. and Hardie, R.C., eds), pp. 317-359, Springer

12 Hausen, K. (1981) Monocular and binocular computation of motion in the lobula plate of the fly. Verh. Dtsch. Zool. Ges. 74, 49-70

13 Hausen, K. and Egelhaaf, M. (1989) Neural mechanisms of visual course control in insects. In Facets of Vision (Stavenga, D.G. and Hardie, R.C., eds), pp. 391-424, Springer

14 Egel haaf, M. and Borst, A. (1993) A look into the cockpit of thefly: Visual orientation, algorithms, and identified neurons. J . Neurosci. 13, 4563-4574

15 Egelhaaf, M. and Warzecha, A-K. (1999) Encoding of motion in real time by thefly visual system. Curr. Opin. Neurobiol. 9, 454-460

16 Bialek, W. and Rieke, F. (1992) Reliability and information transmission in spiking neurons. Trends Neurosci. 15, 428-433

17 Warzecha, A-K. and Egelhaaf, M. (2001) Neuronal encoding of visual motion in real-time. In Motion Vision: Computational, Neural, and Ecological Constraints (Zanker, J .M. and Zeil, J ., eds), pp. 239-277, Springer

18 deRuyter van Steveninck, R. et al. (2001) Real-timeencoding of motion:Answerable questions and questionableanswers from thefly's visual system. In Motion Vision: Computational, Neural, and E cological Constraints (Zanker, J .M. and Zeil, J ., eds), pp. 279-306, Springer

19 Kern, R. etal. (2001) Neural processing of naturalistic optic flow. J . Neurosci. 21, 1-5

20 Lewen, G.D. et al. (2001) Neural coding of naturalisticstimuli. Network: Comput. Neural Syst. 12, 317-329

21 Heisenberg, M. (1997) Genetic approaches to neuroethology. BioE ssays 19, 1065-1073

22 Miklos, G.L. and Maleszka, R. (2000) Deus ex genomix. Nat. Neurosci. 3, 424-425

23 Sandini, G. et al. (2001) Therole of inertial and visual mechanisms in the stabilization of gazein natural and artificial systems. In Motion Vision: Computational, Neural, and Ecological Constraints (Zanker, J .M. and Zeil, J ., eds), pp. 189-218, Springer

24 Lappe, M., ed. (2000) Neuronal Processing of OpticFlow, Academic Press

25 Srinivasan, M.V. et al . (1999) Motion detection in insect orientation and navigation. Vis. Res. 39, 2749-2766

26 Hengstenberg, R. (1993) Multisensory control in insect oculomotor systems. In Visual Motion and its Rol ein theStabilization of Gaze(Miles, F.A. and Wallman, J ., eds), pp. 285-298, Elsevier

27 Krapp, H. (2000) Neuronal matched filters for optic flow processing in flying insects. In Neuronal Processing of Optic F low (Lappe, M., ed.), pp. 93-120, Academic Press

28 Douglass, J .K. and Strausfeld, N.J . (2001) Pathways in dipteran insects for early visual motion processing. In M otion Vision: Computational, Neural, and E cological Constraints (Zanker, J .M. and Zeil, J ., eds), pp. 67-81, Springer

29 Krapp, H.G. et al. (1998) Dendritic structureand receptive-field organization of opticflow processing interneurons in thefly. J . Neurophysiol. 79, 1902-1917

30 Krapp, H.G. et al. (2001) Binocular contribution to optic flow processing in thefly visual system. J. Neurophysiol. 85, 724-734
31 Karmeier, K. etal. (2001) Early visual experience and receptivefield organization of the optic flow processing interneurons in the fly motion pathway. Visual Neurosci. 18, 1-8

32 Petrowitz. R. et al. (2000) Arrangement of optical axes and thespatial resolution in the compound eye of the female blowfly Calliphora. J . Comp. Physiol. 186, 737-746

33 Krapp, H. and Egelhaaf, M. (1999) Local preferred directions of visual widefield neurons and the compound eyegeometry of the blowfly Calliphora erythrocephala. In Göttingen Neurobiology Report (Elsner, N. and Eysel, U., eds), p. 440, Thieme

34 Zeil, J . (1989) Spatial vision in a flat world: Optical and neural adaptations in arthropods. In Neurobiology of Sensory Systems (Singh, R.N. and Strausfeld, N.J ., eds), pp. 123-137, Plenum Press

35 Wehner, R. (1997) I nsect navigation: Iow-level solutions to high-level tasks. In From Living Eyes to Seeing Machines (Srinivasan, M.V. and Venkatesh, S., eds), pp. 158-173, Oxford University Press

36 Virsu, V. and Hari, R. (1996) Cortical magnification, scaleinvariance and visual ecology. Vis. Res. 36, 2971-2977

37 Strausfeld, N.J . etal. (1995) Oculomotor control in Calliphorid flies: GABAergic organization in heterolateral inhibitory pathways. J . Comp. Neurol. 361, 298-320

38 Horstmann, W. et al . (2000) Synapticinteractions increase opticflow specificity. Eur. J . Neurosci. 12, 2157-2165

39 Haag, J . and Borst, A. (2001) Recurrent network interactions underlying flow-field selectivity of visual interneurons. J . Neurosci. 21, 5685-5692

40 J ohnston, D. and Wu, M.S. (1995) Foundations of Cellular Neurophysiology, MIT Press

41 Koch, C. (1999) Biophysics of Computation, Oxford University Press

42 Kurtz, R. et al. (2001) Transfer of visual information via graded synapses operates linearly in thenatural activity range. J . Neurosci. 21, 6957-6966

43 Warzecha, A-K. and Egel haaf, M. (1999) Variability in spike trains during constant and dynamic stimulation. Science 283, 1927-1930

44 Warzecha, A-K. et al. (2000) Reliability of a fly motion-sensitiveneuron depends on stimulus parameters. J . Neurosci, 20, 8886-8896

45 Barberini, C.L. et al. (2001)A comparison of spiking statistics in motion sensing neurons of flies and monkeys. In Computational, Neural and Ecological Constraints of Visual Motion Processing (Zanker, J .M. and Zeil, J ., eds), pp. 307-320, Springer

46 Mainen, Z.F. and Sejnowski, T.J . (1995) Reliability of spiketiming in neocortical neurons. Science268, 1503-1506

47 Nowak, L.G. et al. (1997) I nfluence of low and high frequency inputs on spiketiming in visual cortical neurons. Cereb. Cortex 7, 487-501

48 Haag, J . and Borst, A. (1996) Amplification of high frequency synaptic inputs by active dendritic membrane processes. Nature379, 639-641

49 Kretzberg, J . et al. (2000) Membrane potential fluctuations determinethe precision of spike timing and synchronous activity: A model study. J . Comput. Neurosci. 10, 79-97
50 Borst, A. and Egelhaaf, M. (1989) Principles of visual motion detection. Trends Neurosci. 12, 297-306

51 Haag, J . and Borst, A. (1997) Encoding of visual motion information and reliability in spiking and graded potential neurons. J . Neurosci. 17, 4809-4819

52 Warzecha, A-K . et al. (1998) Temporal precision of theencoding of motion information by visual interneurons. Curr. Biol. 8, 359-368

53 deRuyter van Steveninck, R. and Bialek, W. (1995) Reliability and statistical efficiency of a blowfly movement-sensitiveneuron. Philos. Trans. R. Soc. London Ser. B 348, 321-340

54 Schilstra, C. and van Hateren, J.H. (1999) Blowfly flight and opticflow. I. Thorax kinematics and flight dynamics. J . Exp. Biol. 202, 1481-1490

55 van Hateren, J .H. and Schilstra, C. (1999) Blowfly flight and optic flow. II. Head movements during flight. J . Exp. Biol. 202, 1491-1500

56 Warzecha, A-K. and Egelhaaf, M. (1997) How reliably does a neuron in the visual motion pathway of thefly encode behaviourally relevant information? Eur. J . Neurosci. 9, 1365-1374

57 Kimmerle, B. and Egelhaaf, M. (2000) Performance of fly visual interneurons during object fixation. J . Neurosci. 20, 6256-6266

58 Kern, R. etal. (2000) Neural representation of optic flow experienced by unilaterally blinded flies on their mean walking trajectories. J . Comp. Physiol . 186, 467-479

59 Kern, R. etal. (2001) Neuronal processing of behaviourally generated optic flow: Experiments and model simulations. Network: Comput. Neural Syst. 12, 351-369

60 Dror, R.O. et al. (2001) Accuracy of velocity estimation by Reichardt correlators. J . Opt. Soc. Am. 18, 241-252

61 O'Carroll, D.C. et al. (1996) Insect motion detectors matched to visual ecology. Nature 382, 63-66

62 O'Carroll, D.C. et al. (1997) Spatio-temporal properties of motion detectors matched tolow image vel ocities in hovering insects. Vis. Res. 37, 3427-3439

63 Maddess, T. and Laughlin, S.B. (1985) Adaptation of the motion-sensitiveneuron $\mathrm{H} 1$ is generated locally and governed by contrast frequency. Proc. R. Soc. London Ser. B 225, 251-275

64 Harris, R.A. et al. (2000) Contrast gain reduction in fly motion adaptation. Neuron 28, 595-606

65 Kurtz, R. et al. (2000) Dendritic calcium accumulation associated with direction selective adaptation in visual motion sensitiveneurons in vivo. J . Neurophysiol. 84, 1914-1923

66 Fairhall, A.L. et al. (2001) Efficiency and ambiguity in an adaptiveneural code. Nature 412, 787-792

67 deRuyter van Steveninck R. et al. (1986) Adaptation of transient responses of a movementsensitiveneuron in the visual system of the blowfly, Calliphora erythrocephala. Biol. Cybern. 54, 223-236

68 Borst, A. and Egelhaaf, M. (1987) Temporal modulation of luminance adapts time constant of fly movement detectors. Biol. Cybern. 56, 209-215

69 Harris, R.A. et al. (1999) Adaptation and the temporal delay filter of fly motion detectors. Vis. Res. 39, 2603-2613

70 Egelhaaf, M. et al. Outdoor performance of a motion-sensitiveneuron in the blowfly. Vis. Res. (in press) 